\title{
Videogames and Inclusive Education Project in Palermo Secondary School
}

\author{
Giuseppa Cappuccio
}

\begin{abstract}
Attempting to support videogames for education and learning purposes has prompted considerable attention over the last years. The great variety of digital games available has provided much for educators and researchers to explore, resulting in intense disputes that many games have benefits both in and out of the classroom for learners of secondary school. Many games have been revealed as strong educational tools for their design as well as their effective implementation in the classroom. Thus far, research on the impact and outcomes of this pedagogy is somewhat limited, but promising. Further projects and evaluations are required to provide the support needed in order to encourage more teachers and schools to adopt these practices, and the early results are to be confirmed in further studies. Videogames are being increasingly used in initiatives to promote personal empowerment and social inclusion of disadvantaged students through learning and participation.

This paper describes there search for the development of mathematical, linguistic and'soft' skills,in the Academic Year2014/2015with 10 teachers and102students attending Secondary School, 1st year, located in tough areas of Palermo (Sicily). The project involves students and teachers, for 60 hours, who will experience a media education training methodology for the promotion of mathematical, linguistic and 'soft' skills.
\end{abstract}

Index Terms-Video games, media education, inclusive education, research.

\section{INTRODUCTION}

Can we learn socially and academically valuable concepts and skills from video games? How can we best teach the "gamer generation?" How can educators and curriculum designers harness the participatory nature of digital media and play?

Video games were developed with a double mission: to stimulate the extraordinary, but also the ordinary. Videogames present a new form of amusement, which has put the classical model of playing into crisis, where the dimensions of space and time have to be clear and defined beforehand. The emblematic situation is characterized by infinitive simulations in which the player can in theory play an endless game, without reaching a well defined objective if not

Manuscript received October 12, 2015; revised December 22, 2015. This work was supported in part by the Research Project of National Interest (PRIN, 2010/2011) "Success training, inclusion and social cohesion: innovative strategies, ICT and valuation models" (Scientific Coordinator of the National Research Programme is Professor Gaetano Domenici). Starting from the standard measurement of learning, achieved through an external evaluation integrated with the internal evaluation prepared by the teachers, the Research Unit of Palermo, coordinated by Professor Giuseppe Zanniello, aims at both improving individual performance of pupils and teachers' professional skills.

G. Cappuccio is with the Psichological and Educational Science Department, University of Palermo, Italy (e-mail: giuseppa.cappuccio@unipa.it). the infinitive length of the game itself. The term "video game" derives from the method that is used to carry out this entertaining activity: in front of a screen or a monitor, the player interacts in an imaginary world of video games through a joystick or any other instrument of interaction between man and machine. Paying attention to the term video game, one can note that the component "game" puts in evidence the aspect of entertainment; from the pleasant action there comes also a sense of competition based on certain rules. In the context of empowerment and inclusion initiatives, the possibility to reach out to those at risk in a highly individualized way presents a welcomed opportunity. Continued participation in education and training, for instance, is shaped by the degree to which people can be guided and mentored in a personalized manner.

The reflection contained in this contribution is proposed to analyse the challenge of education launched by the cultural and social phenomenon of videogames, which have become less and less an object of pure entertainment but an increased metaphor of the great game which is the reality of life itself. Video games are an illustrious presentation of contemporary culture; the intellectual and emotional territory of experimentation, of the creation of new languages, of social interaction and exploration of the world. In the course of a few years, video games have demonstrated to have all that is required to assume an emerging and complex role both in contemporary and future culture. The view proposed here focuses on the potential of videogames, not only as educating instruments but also as objects of education. On the one hand, videogames represent a kind of educating instrument, because their use can motivate pupils to involve themselves into activities. Using television and computers to teach any subject, say Science, ICT, History, with the assumption that such technologies are a neutral means of information delivery is not Media education. On the other hand, videogames can be considered as objects of education because they can develop both critical understanding and active participation. They enable secondary school students to interpret and make informed judgements as consumers of media; but they also enable them to become producers of media in their own right, and thereby to become more powerful participants in society. Video games education is about developing young people's critical and creative abilities. The educational process should be constantly improved to reach a higher level of students' perceived knowledge according to their potential. Different approaches, methodologies and teaching practices must be adopted and put into practice so that positive results can be achieved at the end.

This manuscript describes there search for the development of mathematical, linguistic and 'soft' skills, in the Academic 
Year2014/2015with10 teachers and 102students attending secondary School, $5^{\text {st }}$ year, located in difficult areas of Palermo. The project involves students and teachers, for 60 hours, who will experience a media education training methodology for the promotion of mathematical, linguistic and 'soft' skills. We believe that the idea of learning through games can improve the learning process, if computer and mobile video games are developed to incorporate adequate pedagogical components, based on didactic principals as highly organized and properly guided pupils' activities. We follow this idea in this study, while trying to present research findings that support it. The learned skills and content through such learning activities can be successfully transferred outside of the gaming environment with increased students' motivation.

\section{VIDEOGAMES FOR INCLUSIVE EDUCATION}

Today an estimated 110 million people are at risk of social exclusion in Europe. This presents society, entrepreneurs and policy makers with a challenge that calls for social innovation of all types to tackle low skills, unemployment, discrimination, barriers to disabled people, poor health and other factors associated with social exclusion. A large number of studies show that social exclusion is a complex and multi-faceted process that is caused by dynamics that are often intertwined and as such strengthen each other and often lead to simultaneous deprivation at the level of work, education, living conditions, income, social security, daily resources or health [1]-[4]. Consequently, factors like health, education, employment and equitable participation are brought to the fore as key priorities in social inclusion policies. Bianchi et al. [5] state that inclusion policies should have an augmented focus on employment and education and training.

The e-Europe Advisory Group [6] proposed the term e-Inclusion to refer to the effective participation of individuals and communities in all dimensions of the knowledge-based society and economy through their access to ICT, made possible by the removal of access and accessibility barriers, and effectively enabled by the willingness and ability to reap social benefits from such access. Further, e-Inclusion refers to the degree to which ICT contributes to equalizing and promoting participation in society at all levels (i.e. social relationships, work, culture, political participation, etc.).

Marc Prensky [7] suggests that "our students have changed radically. Today's students are no longer the people our educational system was designed to teach. Today's students represent the first generations to grow up with this new technology. They have spent their entire lives surrounded by and using computers, videogames, digital music players [...] what should we call these new students of today? The most useful designation I have found for them is Digital Natives. Our students today are all "native speakers" of the digital language of computers, video games and the Internet. Those of us who were not born into the digital world but have, at some later point in our lives, become fascinated by and adopted many or most aspects of the new technology are, and always will be compared to them, Digital Immigrants".
Videogames personalize the use of media since they transform each one to become a solitary actor in the communicative context. They are the voice of a general imaginary group since, as McLuhan [8] states "any game, as a medium of communication, is an extension of an individual or a group. Its effect on the group or on the individual consists in giving a new consideration on those parts of a group or an individual that have not been extended".

Video games have a great positive potential in addition to their entertainment value and there is considerable success when games are designed to address a specific problem or to teach a certain skill. Video games can clearly consume the attention of children. However, it is important to assess the extent of their impact on childhood education. Thanks to inclusive education, students can access learning in its creative, challenging nature, and may find an answer to their learning needs. Video games can provide an alternative to traditional text-based narrative because they help combine literacy learning with creativity and problem solving. Video games can even enhance self-esteem when it comes to learning and help engage our students. They match pedagogical practices and can create learning opportunities and challenges for all learners [9], [10].

Video game technology brings new challenges to the education arena. Video games represent one technique that may be available to the classroom teacher as well as to his/her students. Video games have some characteristics that make them unique in relation to other forms of entertainment. First of all, the presence of a screen which quickly provides an exceptional visual connotation. In videogames the predominating method of communication is principally graphical and visual. A video game is not only video: it's also audio, text, animation; it encloses in itself all types of media languages transforming the activity in a sort of communication using many channels. All these channels interact among themselves to form a final product which is used as something that is very attractive, involving and intense.

Video games are no longer limited to corporate-built consoles, thanks to the Wi-Fi accessible smartphones and tablets that are shaping entertainment for a new generation of players. Thanks to miniaturization and possibility to implement mobile video games, today's mobile games are an increasingly notable and growing area of game business and culture. An expanding range and increasing number of video games are being produced and published for handheld consoles, mobile phones and tablet devices [11].

The study of video games in education and its implications for teaching and learning are at a critical point. Kafai [12] believes that the special role of video games in contemporary children's culture creates an opportunity to study, playing and making games for learning. Moreover, video games may provide progressive and complex learning environments that will prepare them to face the challenges in their real lives.

Salen and Zimmermann [13] in their detailed exploration of game design, suggest that games may be approached with a focus on rules (the design of game), play (the human experience of playing the game), or culture (the larger context engaged with and inhabited the game). 
Students of the Net generation live in media-saturated environments as they spend an average of $6.5 \mathrm{hr}$ per day engaged with various media [14]. Educators and scientists repeatedly return to the conclusion that one advantage of educational games is that games tend to generate a much higher level of students' positive emotional engagement, thus making the learning experience more motivating and appealing, improving participation and achievement [15]. Games can motivate passive students to contribute more than they would in a traditional learning environment [16]. Video games motivate learning by challenging and providing curiosity, beauty, fantasy, fun, and social recognition. They reach learners who do not do well in conventional settings [17]. The development of metacognitive skills is a topic of great relevance for the impact that it has on academic performance, lifestyle and in the way one interacts with the surrounding environment. In this sense, it can be said that the actions orientated towards the promotion of metacognitive skills imply the enhancement of lifestyle and the creation of flexible and mature personality traits [18].

A player learns to think critically about the simulation while at the same time gaining embedded knowledge through interacting with the environment. By allowing the player to take on new identities, solve problems through trial and error, and gain expertise or literacy, video games have potential for nonself-referential disciplines, particularly science [19]. Games provide learners the opportunity to learn by doing, experience situations first-hand, and role-play. Authentic activity is important for learners, because it is the only way they gain access to the standpoint that enables practitioners to act meaningfully and purposefully [20]. This establishes the proliferation of gaming in today's learners [21].

Tanoni [22] talks of collocation instead of insertion and indicates the formula "play to learn, learn to play" as the base for modern learning, based on motivational stimulation, which in this case would derive from the joyful use of video games at school; without transforming the class in a game room naturally, but with the intention of integrating the canonical formulas of teaching and learning using new languages.

The learning environment must be responsive regarding the actions of the person that is targeted. A responsive environment consists of the following elements: it gives the players a chance to explore things freely, it informs the player about the consequences of his/her chosen actions and it evolves at the pace of the player. A reflexive learning environment needs to enable people to create a reflexive image of themselves so that they can see themselves as a social subject, from the point of view of others. This is a common practice in sport activities, where trainers will look back at a match with their trainees to learn about their weaknesses and strengths for example.

The personalization principle is also relevant in a game space, because games have the capacity to include a feedback mechanism and let players 'explore' the game world freely. The game space or world also creates the opportunity to let a player reflect about their position vis-à-vis their goals [23]. This is a result of the feedback mechanism that can be included in a game space, but also the result of rankings, scores, trial and error and being able to see consequences of certain actions or behaviours [24].

Games used in education aim to stimulate learning in the stricter sense aiming to convey knowledge and improve skills. In a school context, they can involve both classroom and home usage. The range of subjects covered by games used in education is broad and can be linked to certain subjects such as history, mathematics, foreign languages, biology It is important to note that games in education generally do not aim to replace but rather to complement traditional course materials by providing interactive ways to engage with content or to exercise [25]. Some other studies [26], [27] revealed that violent videogames may be more harmful than violent television and movies because they are interactive, very engrossing and require the player to identify with the aggressor. Violent videogames provide a forum for learning and practicing aggressive solutions to conflict situations, believed Anderson. In the short run, playing a violent video game appears to affect aggression by priming aggressive thoughts. Longer-term effects are likely to be longer lasting as well, as the player learns and practices new aggression-related scripts that can become more and more accessible for use when real-life conflict situations arise.

Videogames can clearly consume the attention of children and adolescents. However, it is important to assess the extent that videogame technology had an impact on childhood education.

It must be acknowledged that the activities of video game education require technologicalequipments, which don't have an exaggerated cost in themselves. However, they are not present in secondary schools because they are badly considered, according to prejudicial believes [19].

In addition, these activities require a lot of time; which is difficult to fit in the organizational structure of school time and personal time, since these activities require specific expertise that most of the time teachers do not possess.

Media education can be configured as a strategic element in the education of a person as a whole. The application of the principles and objectives of media education in the field of video games is quite recent and there are many more open questions than established procedures, but they are very interesting. I agree with Buckingham [28] and Jenkins [29], who believed Media Education is the process of teaching and learning about media and aims to develop both critical understanding and active participation. It enables young people to interpret and make informed judgements as consumers of media in their own right. Indeed, Media education is about developing young people's critical and creative abilities.

\section{A RESEARCh PROJECT ON VIDEOGAMES AND INCLUSIVE EDUCATION}

The paper here presented is part of the Research Project of National Interest (PRIN, 2010/2011) "Success training, inclusion and social cohesion: innovative strategies, ICT and valuation models" (Scientific Coordinator of the National Research Programme is Professor Gaetano Domenici). Starting from the standard measurement of learning, achieved 
through an external evaluation integrated with the internal evaluation prepared by the teachers, the Research Unit of Palermo, coordinated by Professor Giuseppe Zanniello, aims at both improving individual performance of pupils and teachers' professional skills.

The expansion of gaming is significant also in terms of quality, as games have become a site for innovative, new play and game design practices. Many of the novel innovations that video games have introduced benefit from the specific characteristics of the media ecosystem, including the online digital distribution channels, new interface modalities, and sensor capabilities available in modern mobile device.

Video games are being advocated as powerful motivational and learning tools for various reasons, yet a number of these claims remain hypothetical and require further exploration and validation through empirical research.

The present research contains a design for the development of mathematical, linguistic and'soft' skills, in the Academic Year2014/2015with102students attending secondary School, 1st year, located in tough areas of Palermo. The project involves students and teachers, for 60 hours, who will experience a media education training methodology for the promotion of mathematical, linguistic and 'soft' skills.

\section{A. Hypothesis}

We suppose that videogames in learning can develop knowledge, mathematical and linguistic skills and can support the development of key competences, including digital competence, creativity and innovation, citizenship, and lifelong learning. They can also develop 'soft' skills including strategic thinking, planning, negotiating skills, group decision-making as well as eye-hand coordination.

According to Haché \& Cullen [30] we expect the following positive effects through the usage of video games to enhance social inclusion:

1) Improved numeracy and literacy

2) Development of digital literacy

3) Supporting team-working

4) Increasing motivation to learn more

5) Reduced marginalisation

\section{B. Methodology}

The research project has involved two phases.

The first phase is aimed at analyzing videogame products through an evaluation grid [31], [32] divided into three areas, each one consisting of items that may either structure a possible discussion led by teachers, pedagogues, educators and parents or address a child's independent work. The first area identifies the synthetic information of the game on which one has chosen to work, elements available directly from its package or on related websites. The second area concerns the analysis of the content in the game chosen. In particular, this section forces one to dwell on the narrative and representational aspects of the game, investigating the characteristics of the plot of the story, its setting, the characters and their characteristics. The third area allows one to reflect on the formal elements of the game, such as the graphics, the pace, the quality of the images.

The second phase is aimed at testing and analysing teaching methods. In this phase we have distinguished three potential ways of using video games in the classroom:

1) Developing skills and abilities: from specific skills like deductive reasoning or memorization, to more contextual ones like co-operation and communication skills, drawing up a list of potential developments through games, with integration in a classroom setting.

2) A stimulus for learning: the game sessions used as a starting point for other activities such as creative writing or charts analysis. Video games influence affective and motivational aspects.

3) Content related learning: the content in the game presented in a very different way as it usually is in the classroom. Simulations remain the games with the greatest potential to directly teach contents, but the accuracy of their driving models has to be irreproachable and learning activities still need to be designed. Games allow direct knowledge and content learning.

Teachers, with the support of researchers, have tried to make concepts and principles directly tangible and to promote experiential learning at different planes (imaginative, emotional and behavioural). Teachers will furthermore identify the most appropriate ways to help students better see and understand the meaning of what they are learning, so that they can perceive its intrinsic value and 'transform' their mathematical and linguistic skills into consistent behaviours.

\section{Target}

The sample consists of 10 Teachers (Italian and mathematic) and 102 students of the first year of secondary schools in Palermo.

\section{Assessment Methods}

We used different assessment tools in order to monitor and evaluate initial competences, intermediate improvements and final outcomes of the project. The overall strategy is aimed at improving the teaching skills of school teachers involved in the research.

Before designing the exercises and the methods suitable for the evaluation of the intervention results, we clearly defined which characteristics are most relevant for scholastic success. The initial assessment of students' characteristics required triangulation, comparison and integration of information gathered from different sources.

The use of an observation grid to value videogames, previously built and validated, allowed teachers to gain along the way - a clear awareness of the outcomes of their videogames teaching.

With teachers aid we developed a rubrics evaluation. Each rubric was developed to reveal students improvement of mathematical and linguistic skills and of key competences, including digital competence, creativity and innovation, citizenship, and lifelong learning.

\section{E. Experimental Process}

The experiment was articulated into three main steps: a) analysis of videogames, b) designing and developing media education teaching materials and modules, c) testing media education teaching materials.

In the first step (June - September 2014), teachers analysed 40 video and digital game products with the evaluation grid 
and they selected the following games in order to design their media teaching activities: Disney Magical World (3D), Plants VS Zombies: Garden Warfare (3D), Little Big Planet 3 (3D), Scoop for math, Cut The Rope 2 (2D).

In the second step, the purpose was to plan and develop, with teachers, four media education modules regarding video and digital games. The activity of developing teaching materials took place from October to November 2014 and was coordinated by university researchers. Each one of those modules is composed of eight activities.

The project activities were coordinated within the State's secondary education curriculum, applying interactive playing/gaming methods, adopting knowledge outside the classroom walls, organizing various workshops, and using the computer technology as an auxiliary tool to the learning activities. A special course was developed instructing the teachers how to coordinate video games activities with the regular lectures from the predetermined curriculum. Students were also involved in the research of the old and forgotten outdoor games, wrote about themselves with the help of their grandparents, prepared a video demonstrating how each game is played and shared it with the fellow students from another school.

Through the video games students were progressively introduced into different situations, helping them to develop their critical thinking by:

- considering how they can influence their classmates to prefer playing video games in groups instead;

- recognizing the advantages for learning while playing the video games and establishing a logical links between the each game and the required objectives;

- interpreting the findings, performing self evaluation and developing the skills to ask critical questions and lead to productive discussion.

Mathematical and linguistic concepts were taught according to the cognitive skills and abilities of the students, while solving specific problems via different video games thus enhancing the process of logical thinking, ability to analyse, synthesize abstractions and generalizations in a pleasant and stimulating learning environment.

The project activities created a bridge between learning and gaming, using technology, thus building up a connection between the world in which students live and the way they learn about the world.

Students - as players - navigate the game space, they constantly receive feedback on their actions and they can compare their performance to that of others. In addition, they can customize their experience by personalizing their character or selecting their preferred difficulty level or play style. Finally, the game environment can adapt its shape and the learning tasks it presents to the user according to certain criteria, such as previous knowledge or skills, making the experience both more enjoyable and more effective. Through game playing, participants acquire digital skills, break out of their social isolation and positively contribute to their community. The work with digital games affords a highly personalized experience: a single play session is always unique as it emerges from the interaction between game and player(s). For this to occur, the environment in which learning takes place needs to be responsive to the learners' actions and help him or her reflect on one's self as a social being.

The activities of digital games provide a safe environment, in which students experiment without suffering the consequences and where they can discuss topics that may be difficult to bring up in everyday life. The digital games enable perspective taking through role-play and a range of digital games allow their players to act and communicate anonymously. The ability to engage with each other without having to disclose one's identity has been suggested to make players feel more equal to each other and thereby less restrained than in everyday life.

This aspect of learning and participation using digital games is relevant for social inclusion initiatives as people at risk have often become disengaged because of negative experiences they had in the past. In the context of a positive and playful environment, where they feel they can discuss their feelings and experiences more openly, they may gain some of the confidence they lack in other contexts. Although the use of games has been varied, no single approach for using games for education has so far emerged, although key aspects of employment of games have often followed the effective use of simulations and have often involved several steps: defining learning outcomes, selecting a simulation, activities, set of activities or game to support the required learning outcome with an appropriate form of assessment, considering an ordering of the games within this set of activities, assignment and assessment process, undertaking the session/s with proper considerations given to outlining the session, learning outcomes strived for and post session debriefing, undertaking assessment of the session participants (self, tutor based or a combination of all).

In the third step, teachers tested the four media education materials in five classrooms of a secondary school of Palermo, with 102students, from December 2014 to April 2015, three hours a week. The teachers linked each game to specific curriculum objectives, offering pre-adolescents a new opportunity for integrated learning, encouraging creativity and imagination during learning through video games. For the first time in secondary school of Palermo students could experimental math and linguistic learning with video games.

\section{RESULTS}

Video games embedded in larger educational activities can be very powerful to involve students. A player learns to think critically about the simulation while at the same time gaining embedded knowledge through interacting with the environment. Games provide learners the opportunity to learn by doing, experience situations first-hand, and role-play.

We observed that, since games are also played at home, they could bridge the gap between home and school. Nevertheless, not all genres of games are concerned, and their role should be to support learning activities organized by the teacher.

Games activities in math and language have motivated passive students to contribute more than they would in the traditional learning environment. Video games have motivated their learning by challenging and providing curiosity, beauty, fantasy, fun, and social recognition. Media education modules have reached learners who did not do well 
in conventional settings context of play.

During the play, pupils learned to discuss and form opinions, make decisions, develop critical and creative thinking for problem solving. Through video games they were able to memorize and reproduce movements, develop different motor skills and learn to be tolerant, self-reflective while developing a sense of "fair play" and tolerance to others The games brought into light some unexpected social aspects, while some overweight and shy students usually reserved during regular class activities, showed an obvious enthusiasm and courage to take active role in the games and accompanying activities.

Results show that enjoyment and identification in the game experience were higher for pupils playing in a domestic context. Pupils who played in a domestic context also scored higher on perceived learning. These differences for enjoyment and identification appear to be related to the technical performance of the game and time played by the pupils. In a school context, the timeframe for play and the IT infrastructure are limited, which has a negative influence on the game experience. Indeed, when keeping the determinants timeframe and IT infrastructure constant, no difference in feelings of enjoyment and identification are found.

We address some issues like the need of accuracy in content: consistency with reality, correct simulations of phenomenon and accuracy of historical facts. Efficient information from the game developers should also be available for the interested teachers. Knowing more exactly what is involved in the game; which contents are presented and how they can affect the player would help the teachers to integrate video games in their classroom.

\section{CONCLUSION}

Our main conclusions strongly support the potential for mainstream video games in education and furthermore in classroom environments.

At the end of the research, the potential for learning with games and simulations results particularly relevant. However, while the research to support the effectiveness of simulations is considerable, recent studies about using leisure games in learning contexts have found challenges with using games and simulations effectively in practice, particularly in terms of setting and assessing specified learning objectives. The use of both leisure (commercial-off-the-shelf) games and proprietary games needs to be embedded in practice effectively and in accordance with sound pedagogic principles and design. In either case, there is clearly a need for more rigorous baseline studies that can quantify how much and in which ways games and simulations are currently being used most effectively to support learning.

The use of game mechanics in non-game activities is only beginning to receive academic attention. It has been argued that we need more research on the benefits and risks tied to the variety of gamification approaches that are out there.

The rapidly changing landscape of games and simulation development is bringing new potential for learning in immersive worlds using multiple media. Moreover, the speed of uptake in leisure contexts and the expectations of younger learners in particular have deep implications upon how game-based learning will be used in practice. With a greater emphasis upon learning experiences, game-based learning may provide significant challenges to our institutions and teaching strategies, however, it may also provide new opportunities for reconsidering how we learn and for supporting the development of new immersive spaces where learners may produce their own materials, share learning experiences and practice skills for the real world.

\section{REFERENCES}

[1] K Brants and V. Frissen, "Inclusion and exclusion in the information society," Media, Technology and Everyday Life in Europe, Ashgate, ch. 2, pp. 21-33, 2000-2003.

[2] A. Daly, J. McNamara, A. Harding, and M. Yap, "Indicators of risk of social exclusion for children in Australian households: An analysis by state and age group," Australasian Journal of Regional Studies, vol. 14 , no. 2 , pp. $133-154,2008$

[3] G. Jehoel-Gijsbers and C. Vrooman, Explaining Social Exclusion. A Theoretical Model Tested in the Netherlands, The Hague: The Netherlands Institute for Social Research (SCP), 2007.

[4] D. Wright and K. Wadhwa, "Mainstreaming the e-excluded in Europe: Strategies, good practices and some ethical issues," Ethics and Information Technology, vol. 12, no. 2, pp. 139-156, 2010.

[5] A. Bianchi, S. Barrios, M. Cabrera, R. Cachia, R. Compano, N Malanowski, Y. Punie, G. Turlea, D. Zinnbauer, and C. Centeno, Revisiting eInclusion: From Vision to Action, Sevilla, Spain: European Commission, Joint Research Centre (JRC), Institute for Prospective Technological Studies (IPTS), 2006.

[6] Eeurope Advisory Group, EInclusion: New Challenges and Policy Recommendations, Coordinated by Daniel Kaplan for the European Commission, 2005.

[7] M. Prensky, "Digital natives, digital immigrants," On the Horizon, MCB University, vol. 9, no. 5, pp. 1-6, October 2001

[8] M. McLuhan, Understanding Media: The Extensions of Man, New York: McGraw-Hill, 1964.

[9] M. Griffiths, "The educational benefits of videogames," Education and Health, vol. 20, no. 3, pp. 47-51, 2002.

[10] K. Subrahmanyam and P. Greenfield, "Effect of video game practice on spatial skills in boys and girls," Journal of Applied Developmental Psychology, vol. 15, no. 1, pp. 13-32, 1994.

[11] F. Mäyrä, "Mobile games," The International Encyclopedia of Digital Communication and Society, vol. 3, Wiley \& Sons, Inc., pp. 610-614, 2015.

[12] Y. B. Kafai, "Playing and making games for learning instructionist and constructionist. Perspectives for game studies," Games and Culture, vol. 1, no. 1, pp. 36-40, January 2006.

[13] K. Salen and E. Zimmermann, Rules of Play: Game Design Fundamentals, MIT Press, 2004.

[14] D. F. Roberts, U. G. Foehr, and V. Rideout, Generation M: Media in the Lives of 8-18-yearolds, Menlo Park, CA: Kaiser Family Foundation, 2005.

[15] R. Jayakanthan, "Application of computer games in the field of education," The Electronic Library, vol. 20, no. 2, pp. 98-102, 2002.

[16] H. Tanner and S. Jones, "Using ICT to support interactive teaching and learning on a secondary mathematics PGCE course," presented at the British Educational Research Association (BERA), Cardiff University, Cardiff, UK, September 2000.

[17] C. Dede, "Distributed-learning communities as a model for educating teachers," Society for Information Technology \& Teacher Education International Conference, Atlanta, USA, March 2004.

[18] F. Pedone, Enhancement of Styles and Development of Self-regulated Learning, Parma: Junior Editions, 2012.

[19] J. Craft, "A review of what video games have to teach us about learning and literacy," Currents in Electronic Literacy, Marzo, 2004.

[20] J. S. Brown, A. Collins, and P. Duguid, "Situated cognition and the culture of learning," Educational Researcher, vol. 18, no. 1, pp. 32-42, 1989.

[21] W. Rickard and D. Oblinger, "Higher education leaders symposium: Unlocking the potential of gaming technology," presented at the Higher Education Leaders Symposium, Redmond, WA, September 2003.

[22] I. Tanoni, Video Education. From Entertainment to Learning, Milan: Erickson, 2003. 
[23] D. Clark, "Games, motivation \& learning," Caspian Learning, 2007.

[24] T. W. Malone, "Toward a theory of intrinsically motivating instruction," Cognitive Science. vol. 5, no. 4, pp. 333-369, 1981.

[25] P. Wastiau, C. Kearney, and W. Berghe, "How are digital games used in schools?" European Schoolnet.

[26] C. A. Anderson and K. E. Dill, "Video games and aggressive thoughts, feelings, and behavior in the laboratory and in life," Journal of Personality and Social Psychology, vol. 78, no. 4, pp. 772-790, 2000

[27] K. B. Anderson, C. A. Anderson, K. E. Dill, and W. E. Deuser, "The interactive relations between trait hostility, pain, and aggressive thoughts," Aggressive Behavior, vol. 24, no. 3, pp. 161-171, 1998.

[28] D. Buckingham, Media Education: Literacy, Learning and Contemporary Culture, Cambridge: Polity, 2003.

[29] H. Jenkins, Confronting the Challenges of Partecipatory Culture: Media Education for the 21st Century, Building the Field of Digital Media and Learning, MacArthur Foundation, 2006.

[30] A. Haché and J. Cullen, ICT and Youth at Risk: How ICT-Driven Initiatives can Contribute to Their Socio-Economic Inclusion and How to Measure It, Sevilla, Spain: European Commission, Join Research Centre (JRC), Institute for Prospective Technological Studies (IPTS), 2009.

[31] G. Cappuccio, "Analyzing videogames to learn how to think critically," in Proc. 6th International Conference of Education, Research and Innovation, Seville: IATED, pp. 2216-2226, 2013.
[32] G. Cappuccio and G. Compagno, Playing Mind. Learning Activities between "Neuroeducation" and "Video Education", Rome: Aracne, 2015 .

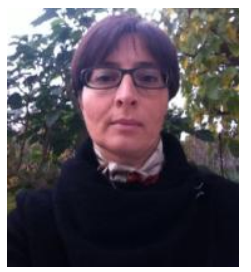

G. Cappuccio was born May 9, 1971. She graduated in educational sciences from the University of Palermo in 1997. She received a Ph.D. in intercultural pedagogy from the University of Messina in the year 2003. She has been an allocator from 01/12/02 to 09/09/05 at the Department in Psychology and Education Sciences and an assistant professor since 15/09/2015. She is associate professor in experimental pedagogy and teaches didactic and experimental pedagogy at the University of Palermo. Her scientific activity has prevalently been carried out in the context of theory of vocational choice, life and career development and didactic for children and media education. This work principally deals with orientative didactics, media education and cartoons and planning didactic- educative courses designed for young children. 